CEPAL REVIEW 87 • DECEMBER 2005

\title{
Towards an efficient innovation policy in Latin America
}

\author{
William F. Maloney and Guillermo Perry
}

I

nnovation has emerged as a central theme on the growth agenda of Latin America. This paper examines four issues. First, how can we know if Latin America really has an "innovation problem" that is behind its weak total factor productivity performance? Second, what do we mean by innovation and what are dimensions of it in which the region exhibits weaknesses? Third, what does recent experience and literature suggest for principles and broad policy measures to foment innovation? Fourth, are there any linkages between these weaknesses and equity? Since even in the Organisation for Economic Cooperation and Development (OECD) there is little consensus on the specific policies that governments should implement, and even less on their suitability to developing countries, this paper attempts to organize thinking around some basic principles and offer suggestive experience rather than specific policy advice.

William F. Maloney

œ wmaloney@worldbank.org

Guillermo Perry

$\infty$ gperry@worldbank.org

Office of the Chief Economist for Latin America and the Caribbean, World Bank 


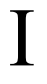

\section{Introduction}

Several issues have led policy makers in Latin America and the Caribbean (LAC) to place "innovation" on the policy agenda. First, the region's growth performance has been modest despite two decades of extensive structural reforms. Since roughly half of cross-country differences in income and growth is attributed to total factor productivity (TFP), the poor TFP growth of Latin America and the Caribbean in the last three decades is a major cause for concern. While in many respects a measure of our ignorance, TFP is often equated to what can be loosely called "technological progress" and, more broadly, to "innovation" (including both technical, institutional, organizational and managerial change and the development of new activities, products and services, both at the firm and the aggregate economy level). Second, much of the discussion on competitiveness is really about productivity, and hence has much to do with the issue of innovation.

Finally, the region's persistent pattern of resourcebased exports raises the questions of where other product lines may come from -consider, for example, forestry giant Nokia's evolution into cell phones in the case of Finland- and whether we can achieve better results with what we have. On the latter point, one of the World Bank's flagship publications, From Natural Resources to the Knowledge Economy, ${ }^{1}$ argued that recent research and the experience of numerous now developed, but resource-based economies suggest that Prebisch was perhaps too pessimistic: resources are neither a curse, nor a destiny that we are bound to follow. In the document in question, our main conclusion was that the region was not getting as much

$\square$ A preliminary version of this study was presented at the seminar "Economic growth with equity: challenges for Latin America" held at ECLAC (Santiago, Chile, 1-2 September 2005).

${ }^{1}$ De Ferranti, Perry, Lederman and Maloney (2002). growth out of its resources as it could, due in part to the now familiar inefficiencies of import substitution industrialization, which penalized those sectors, but perhaps more fundamentally to a lack of national learning and innovative capacity. Latin America's willingness to depend passively on technological transfer from abroad, and its insufficient investments in skills and R\&D may, in the end, have been a dimension of dependency far more damaging than others which have received more attention in the literature.

Hence, as in the OECD, increasingly Latin American and Caribbean policy makers have come to identify trade barriers and lack of incentives for innovation as the main obstacles to further growth and development. In pursuit of the aim of "turning the EU into the most competitive knowledge-based economy in the world" the March 2002 meeting of the European Council in Barcelona announced a goal of increasing average R\&D expenditure from $1.9 \%$ of GDP to $3 \%$ by 2010 so as to close the gap with the United States (2.7\%) and Japan (3.0\%) (OECD, 2004). Latin America's 0.4\% is in a different league altogether (De Ferranti, Perry, Guasch and others, 2003).

This paper takes a step back to examine four issues. First, is the region's weak total factor productivity performance really due to an "innovation problem"? Second, what do we mean by innovation and what are dimensions of it in which the region exhibits weaknesses? Third are there any linkages between these weaknesses and equity: an issue which was also examined at the seminar at which a preliminary version of the present paper was presented? Fourth, what does recent experience and literature suggest for principles and broad policy measures to foment innovation? In view of the lack of consensus on the specific policies that governments should implement and their suitability to developing countries, we have attempted to organize thinking around some basic principles and to offer suggestive experience rather than specific policy advice. 
II

\section{Does Latin America have an innovation problem?}

The issue of innovation is especially sensitive because the theory surrounding it is abundant in examples of market failures which, inevitably, lead to a role that the government must play. In a region whose history has led it to worry so much about government failures, the idea that the market is generating insufficient investment in innovation may imply reversing, to some degree, the tendency over the last 20 years towards reducing the role of public policy in the economy. Understanding the magnitude of the innovation problem is thus important for judging whether the costs of existing market failures indeed exceed the costs of potential government failures in implementing specific innovation policies.

The study by De Ferranti, Perry, Guasch and others (2003), among other analyses, suggests that by common measures of innovation effort and output, the countries of Latin America and the Caribbean lag substantially behind comparable countries. By OECD standards, the region exhibits low levels of R\&D expenditure and private sector participation in $\mathrm{R} \& \mathrm{D}$, low patent production, and high relative importance of basic versus applied research. It also performs relatively poorly against international benchmarks of educational quality and human resources devoted to research and development. Such lags remain even after controlling for per capita income.

These data, though suggestive, in themselves cannot convincingly tell us if we have an innovation problem or not, for several reasons. First, innovation diagnostics often proceed as if the accumulation of knowledge capital were a free-floating activity independent of other factors affecting the level of a country's development. This is not the case, however: globally, there is a very strong positive relationship of TFP with the capital/labour ratio, suggesting that the accumulation of knowledge related capital is complementary to and is driven by many of the same forces determining the accumulation of physical capital (Maloney and Rodriguez-Clare, 2005). In turn, this raises the question of whether a country's perceived innovation shortfall results from problems common to accumulation overall, or whether the activity of innovation itself is somehow especially impeded by specific market, institutional or policy failures.
These likely complementarities also suggest that any discussion on promoting innovation should occur within the context of the climate for promoting accumulation overall. There is a precedent for this broad view in the dual approach the New Zealanders are taking -upgrading their education and science and technology infrastructure, but also focusing heavily on business mentorship, competition policy, and incentives to "get off the island" and export- generally creating a demand for innovation. Many Latin American countries face a similar challenge, and because of their small domestic markets and distance from larger ones they are more like New Zealand than Spain or Italy, which, with their integration into the European Community, gained exposure to energetic forces of competition, other ways of doing business, and broader markets. The danger of not taking this view is that innovation policy may occur as a kind of sexy but isolated activity de-linked from the less glamorous work of finding out why firms may lack dynamism overall.

However, even after accounting for accumulation of human and physical capital, the Latin American countries still appear to have an innovation problem. Maloney and Rodriguez Clare (2005) calibrate a model that allows us to conclude that, given the measured level of accumulation of human and physical capital, many countries in the region show relatively low levels of TFP and implicitly high barriers to innovative activity. The country that they analysed most carefully in terms of data, Chile, appears to have an innovation problem apart from a general accumulation problem.

It is important to note that the calibrated model cannot distinguish between innovation problems and other inefficiencies that drag down TFP. An emerging literature in Chile and elsewhere has stressed the importance of microeconomic adjustment costs as an explanation for poor TFP performance. Caballero, Cowan and others (2004) argue that microeconomic flexibility is the core of creative destruction, productivity increases and economic growth, and that rigidities can be very costly. Focusing on labour legislation, they estimate the effects of job security using a sample of 60 countries for 1980-1998 and find that increasing job security significantly lowers the speed of adjustment to shocks in a third and reduces 
productivity growth by almost $1 \%$ (for countries with strong rule of law, Chile among them). Caballero, Cowan and others (2004) go even further, suggesting that the reduction in productivity growth after 1997 in Chile was due largely to an increase in microeconomic inflexibility, and potentially can reduce structural long run growth by $0.5 \%$ yearly.

While this line of argument is compelling, several pieces of evidence suggest that innovation still remains a strong candidate for explaining deficient TFP and sluggish growth.

First, if we were to explain the TFP gap solely by adjustment costs, Maloney and Rodriguez Clare's calibration suggests that the inefficiencies compared with the United States would appear to be surprisingly large given the extensive micro reforms to date in Chile.

Second, history suggests that deficient national innovative capacity has been a major barrier to postwar Latin American growth. ${ }^{2}$ De Ferranti, Perry, Lederman and Maloney (2002) offer several examples in this respect, perhaps the most illustrative being that of Chile. In the case of the Chilean mining sector, Pinto (1959) argued that local mining companies did not engage in learning by doing in the lower-tech phases of mining and hence "faced with the technological revolution, the local mining companies had behind them neither sufficient accumulated resources, nor the organizational or administrative capacity that were indispensable. In these circumstances, there was no other option but the introduction of foreign capital and expertise." Meller (2001) describes how Chile's technological position continued to deteriorate: "in the 1950s one could have learned more about Chilean copper in foreign libraries than in Chilean ones. Neither was there training of Chilean engineers and technicians specializing in copper." Only in 1965 would Chile develop domestic capacity to analyse the role of the copper industry and educate Chilean professionals and technicians in the management of the large copper firms. Meanwhile, Australia's development of an extensive mining cluster and the University of New South Wales' position as the largest generator of mining engineers in the world perhaps explains why they, and not Chileans, discovered the La Escondida mine, despite the fact that Chile was an exporter of copper well before Australia. Wright (2001) sees innovation issues behind the resource underperformance of Peru and other mining countries as well. Other examples from Mexico and Brazil discussed in De Ferranti, Perry, Lederman and Maloney (2002) show the importance of innovative capacity both for taking advantage of existing areas of comparative advantage and also, presumably, discovering new ones.

Finally, although the argument that "everybody else is doing it" is seldom compelling in itself, it is interesting to note that comparable countries such as Spain and New Zealand -the latter a country whose reform trajectory closely parallels that of the Latin American countries- are focusing heavily on innovation as critical to their future growth.

To be sure, these perspectives on the reasons for deficient TFP are completely compatible. Resolving problems of microeconomic adjustment must be a central part of the innovation agenda, broadly construed as raising the capacity of firms to introduce productivity-improving measures at the firm level.

${ }^{2}$ See Maloney (2002) for a further elaboration of these arguments. 
III

\section{What type of innovation do the}

\section{Latin American countries lack?}

Although the literature often uses R\&D as a conveniently available proxy for innovation effort, both at the aggregate and at the firm level, it is not clear what measures of innovation we should be looking at. Despite the amount that has been written on the importance of R\&D to the learning process and technological transfer, the distinction between adoption and invention gives grounds for suspecting that R\&D may be less important for less developed countries than for more advanced countries. Even within the OECD, some observers argue that the role of $R \& D$ is small compared with the introduction of new organizational and managerial practices. ${ }^{3}$ The question arises, then: what are the ingredients of a good innovation-related strategy for TFP growth? Further, do the differing recipes for achieving growth of the present levels of income all

${ }^{3}$ Comin (2004) argues that in the United States, for example, less that 3 to 5 tenths of a percentage point of the $2.2 \%$ annual growth rate in productivity is attributable to $R \& D$. offer equally sound foundations for future income growth? The answers to these questions clearly affect how we measure innovation deficiencies and how we focus policy in this respect.

A first glance at the use of four commonly cited ingredients involved in technological transfer, adjusted for level of development, suggests some provocative conclusions (Maloney, 2005b). Figure 1 shows that the R\&D trend rises sharply with the development process, but there is substantial variance around this trend, with the Latin American countries generally falling below it. Licensing and tertiary education follow similar trends, although less dramatically, and in these dimensions the region's performance is more mixed. However, just as in the case of the unconditional indicators generally used, we must be cautious using these measures as innovation diagnostics as well. Standard growth theory suggests that investments in innovation, as in the case of physical investments, drive the steady state level of output. Hence, these investment

FIGURE 1

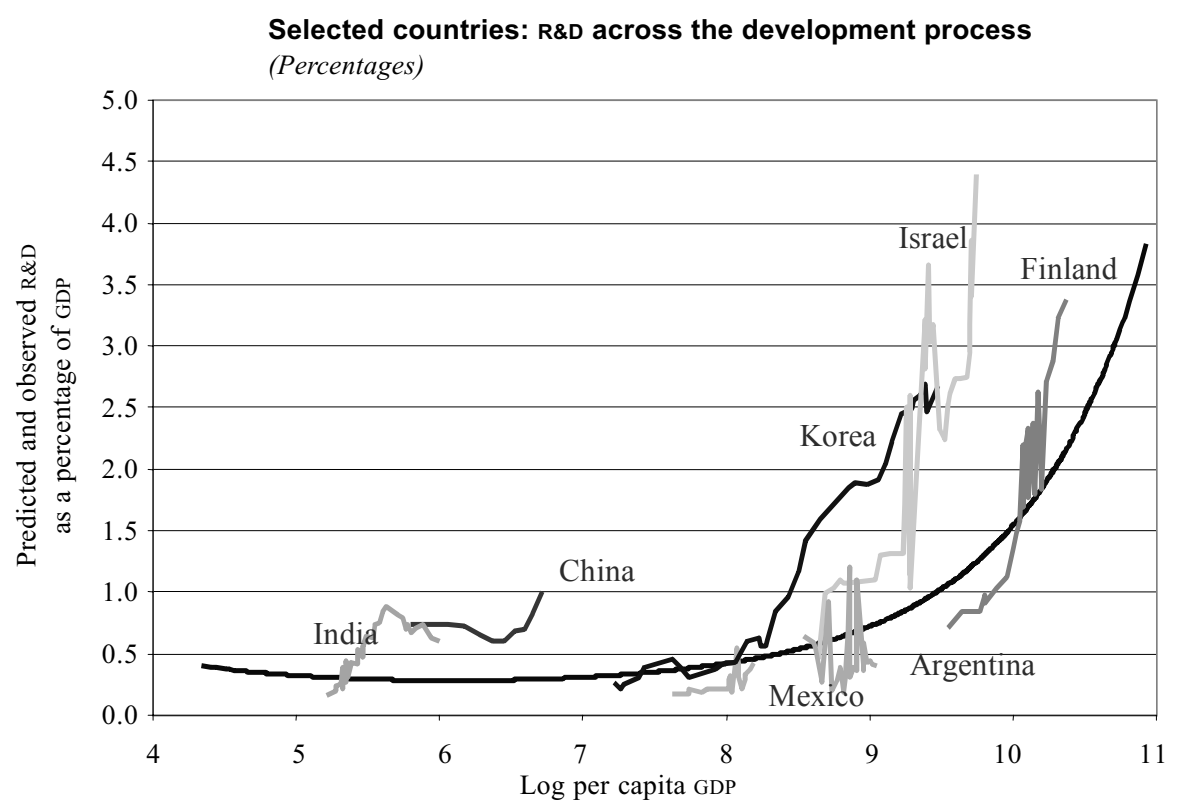

Source: Lederman and Maloney (2003).

TOWARDS AN EFFICIENT INNOVATION POLICY IN LATIN AMERICA • WILLIAM F. MALONEY AND GUILLERMO PERRY 
levels cannot be seen as measures of performance, but rather as recipes for attaining the observed level of income. From a pure efficiency perspective, China's high level of R\&D spending shown in figure 1 may reflect a penchant for technological white elephants, while, less plausibly, Latin America's low levels of tertiary education might reflect hyper-efficient use of those scarce resources. Clearly, economic structure -the fact that Latin America and the Caribbean specialize in goods that, on average, have low "innovation intensities", measured for example as R\&D/value addedalso influences the patterns we see. ${ }^{4}$ Still, two observations are worth making in this respect.

First, the Latin American countries and the hightech miracles have followed very different recipes with regard to R\&D, foreign direct investment (FDI), licensing, and education. Finland and South Korea relied very little on FDI and very heavily on R\&D and licensing of foreign technologies: a pattern that China is also following. This partly reflects their specialization in electronic products, which are especially R\&D intensive. In contrast, Latin America has followed a recipe that has relied little on R\&D or licensing and heavily on FDI. This is a perhaps a worrisome finding, in view of the low rates of technological transfer with FDI documented by numerous authors and even more so in the light of the generally passive approach to the idea of taking advantage of the technological benefits of FDI. In Mexico, for example, although IBм and Hewlett Packard have been present for 30 years in Guadalajara, there is little evidence of a knowledge cluster in computer technologies, at least according to the data available on patent applications (figure 2).

Though often cited as a possible model for the region, Ireland's recipe of relying on extremely high levels of licensing is sui generis and derives from its unique position as an English-speaking bridge from the United States to the European Union: conditions which are not likely to be replicated in our region. The most striking finding is that Spain (and also Italy, though not shown in the figure) appears to follow the Latin American recipe, having made little effort in either R\&D or licensing in order to attain their relatively high levels of income. Spain has converged rapidly to frontier income levels over the last 30 years, and provides an important alternative to the Asian newly industrialized countries as a benchmark for Latin America. This suggests that there is considerable potential in non-R\&D sources of TFP growth, such as the adoption of organizational and management innovation (Caselli and Tenreyro, 2004).

\footnotetext{
${ }^{4}$ Since the analysis was conducted in the light of income and not TFP, this may suggest that high non-innovation accumulation drove income growth, as suggested above.
}

TOWARDS AN EFFICIENT INNOVATION POLICY IN LATIN AMERICA • WILLIAM F. MALONEY AND GUILLERMO PERRY 
FIGURE 2

Selected countries: Deviation from trend for four indicators of technological adoption and capacity, 1972-1998
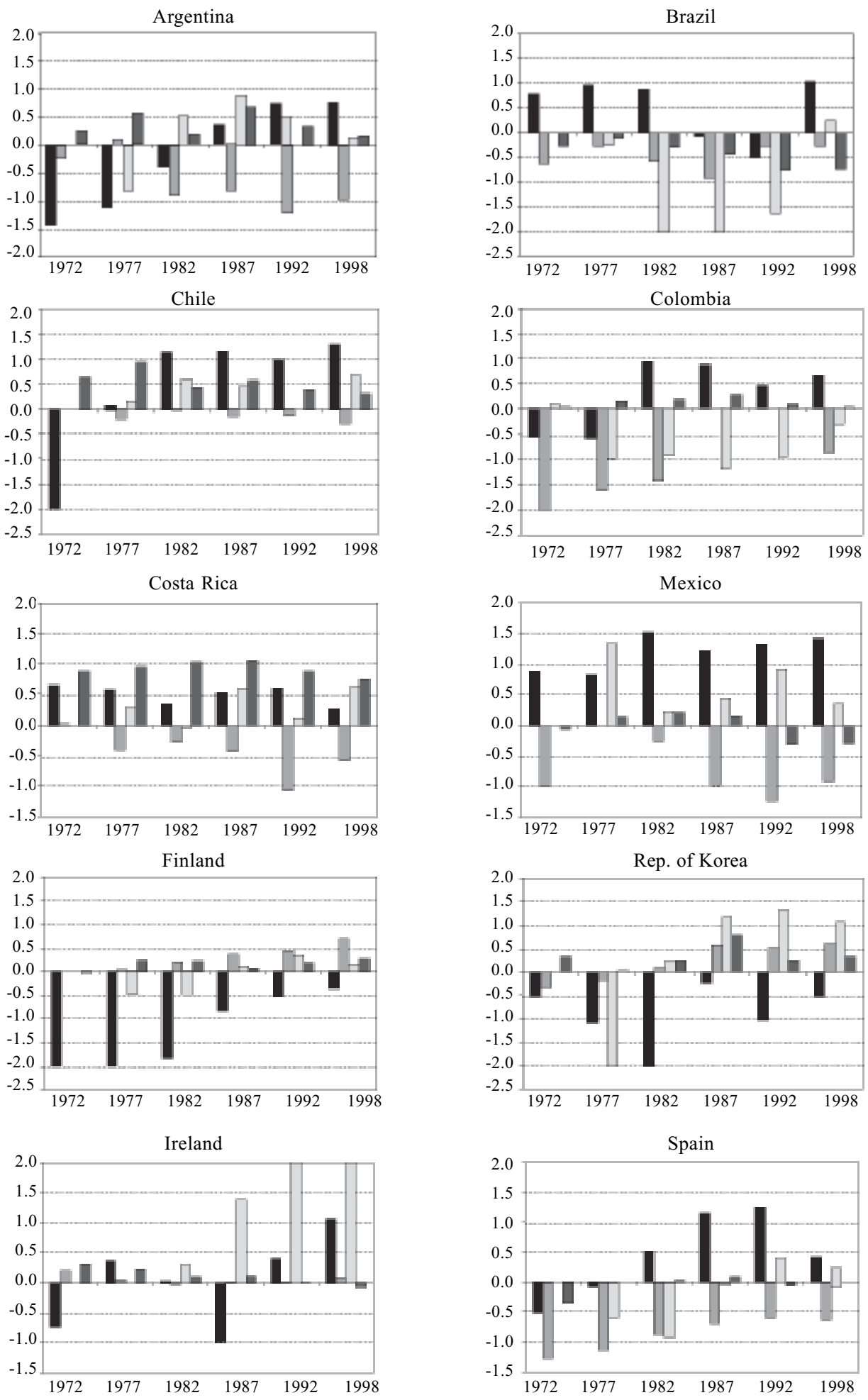

Source: Prepared by the authors. 


\section{IV}

\section{Medium- and long- term innovation policy}

Thus, more attention needs to be paid to fomenting these perhaps less celebrated aspects of innovation over the medium term. Benavente (2004) shows that in, fact, innovations in processes, design, organization etc. are as common in Chile as those in products, which are often associated with R\&D expenditure (figure 3), and this pattern is relatively similar to those we find in the OECD. Figure 4, however, suggests that the actual amounts firms in Argentina and Chile are spending on innovation-related activities as a share of turnover is very low. In the case of Chile, the high heterogeneity among firms within the same sector suggests that increasing the productivity of firms that are well behind the frontier could have substantial effects on TFP growth. ${ }^{5}$

Unfortunately, we do not know much about what makes some firms pursue such innovations and others not, or what policies would encourage them to do so. The system of Technological Centres in Spain has been central to enhancing the capacity of small and mediumsized enterprises, clustering, networking and cooperative activities. The fact that both Spain and Italy have seen large productivity gains by relatively small firms suggests that more research is needed to gain a better understanding of the constraints these firms face and what policies are effective in raising their technological "absorptive capacity"- the ability to use and benefit from existing information. Further, given the complementarities with capital accumulation, the standard litany of needed reform measures in credit, infrastructure, labour markets, etc. also needs to be reviewed with an eye towards their particular implications for innovation.

In addition, a more creative approach to innovation may turn up new areas of comparative advantage for the region. In Italy, for example, sales of the fashion industry now exceed those of the automobile industry. For countries such as Mexico or Colombia with a strong

\footnotetext{
${ }^{5}$ See Bergoeing, Hernando and Repetto (2002) for evidence on Chile. This argument has been stressed by Chen and Dahlman (2004).
}

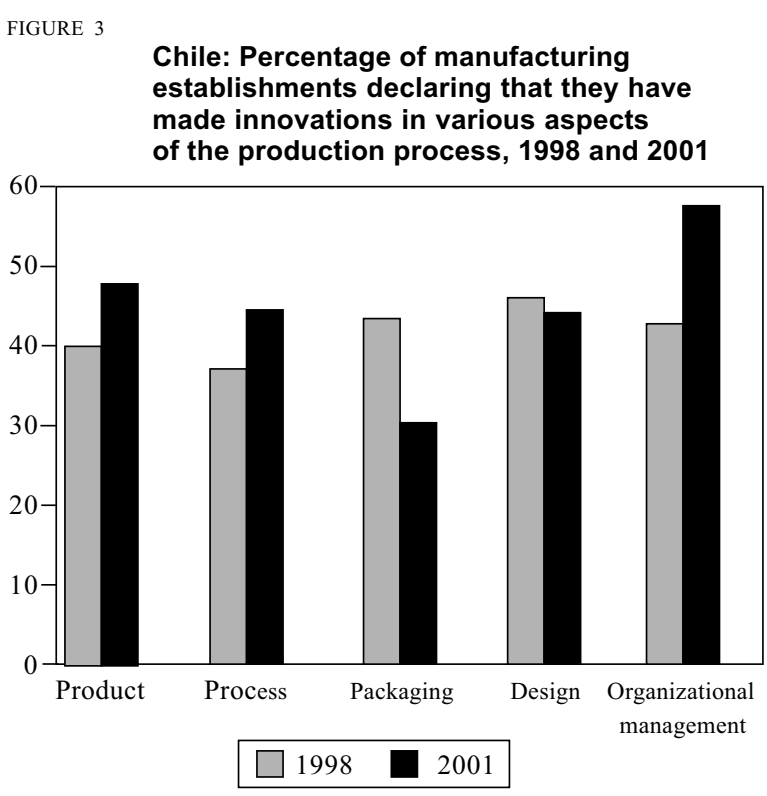

Source: Benavente (2004).

design tradition, investments in these areas may make as much sense as those in science and technology. In more general terms, it is unclear what kind of ingredients are required for the discovery of new areas of comparative advantage of whatever kind, as stressed by Hausmann and Rodrik (2003).

What cannot be overstressed is that, given the relatively little insight we have into the dynamics and choices of firms, we must be very careful that the demand by enterprises for innovation of whatever kind is kept at centre stage in the policy dialogue, lest investments in supply-side measures be rendered useless from the productivity point of view or, still worse, be turned into a sideshow distracting attention from the truly critical issues.

Having said this, investment in science and technology and R\&D is important now and appears even more essential over the longer term for generating sustained growth. First, as initially argued by Cohen and Levinthal (1989), R\&D is essential not only for generating new knowledge, but also for enhancing firms' absorptive capacity. This means that policies to 


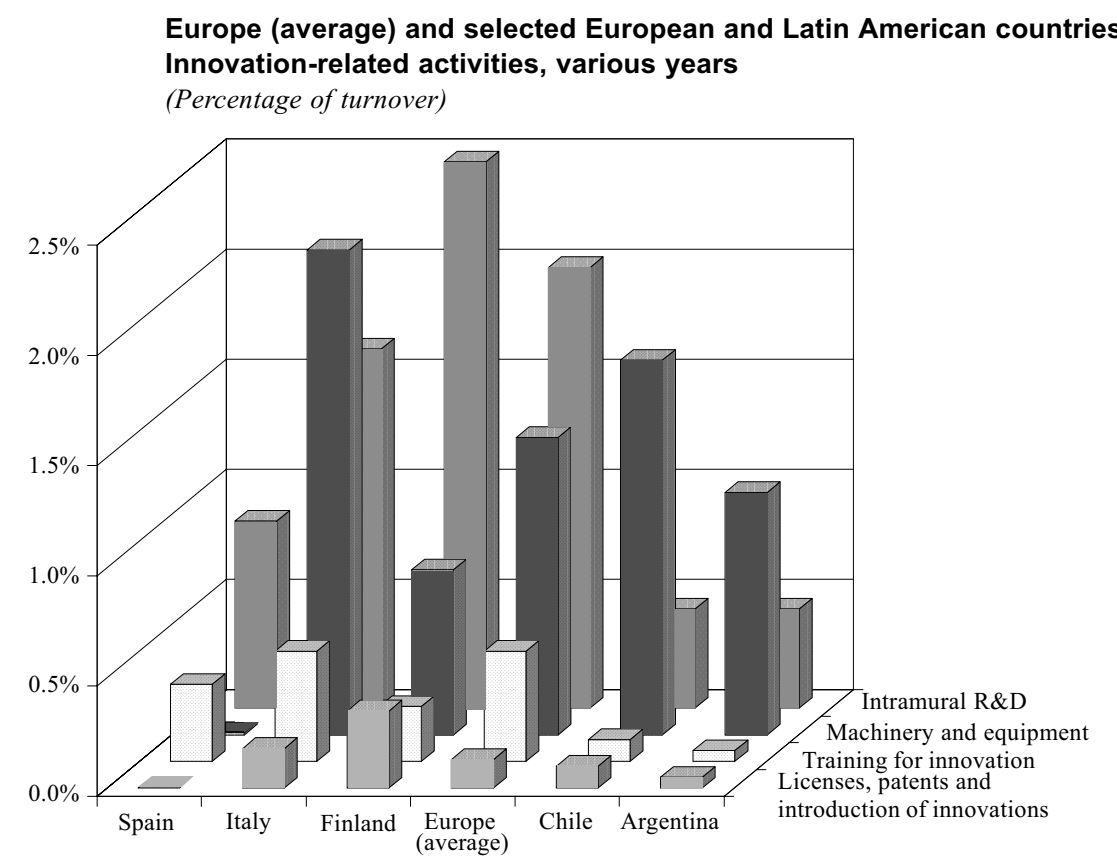

Source: Prepared by the authors on the basis of enterprise innovation surveys in Europe and Chile.

strengthen technology transfer have little value if industry does not have a critical mass of human capital with a highly technical bent able to turn new knowledge into business opportunities. In addition, most technological transfers need significant adaptation to local resources, market conditions, etc, and substantial R\&D is required for this. Much of the R\&D in advanced countries like France is not oriented towards "new" products or techniques, but towards efficient transfer and adaptation of new technologies developed elsewhere.

Second, the slackening recent performance of Italy and Spain suggests that even though Latin America should focus on these broader types of innovations in the medium term, there is no substitute for investments in science and technology, more appropriately captured by R\&D, over the longer term. Italy, with negative TFP growth rates over the last decade, has recently been awarded the honorary "Sick Man of Europe" award by The Economist, partly because of its weak science and technology capacity. Spain has been worried about this and has been aggressively upgrading both its own R\&D efforts and its collaboration with research centers in the rest of Europe. In the context of the convergence club model developed by Howitt and Mayer-Foulkes (2005), limiting itself to the adoption of technologies would doom Spain forever to a lower level of income than those who really invent. ${ }^{6}$ This scenario also appears to haunt other countries with conditionally average levels of R\&D. Denmark, New Zealand, Australia and Canada are increasingly concerned that this has left them as good adopters rather than as countries capable of staying in front in the innovation game, where the big gains appear to lie. Blomström, Kokko and Sjoholm (2002) argue that the application of a similar logic pushed Singapore into a position of being more of a knowledge generator than a mere adopter, in contrast with its previous more typically Latin American stance of relying on FDI and licensing.

Such an effort requires not only increased resources, but also increased efficiency in how those resources are used. De Ferranti, Perry, Guasch and others (2003) suggest that Latin America lags behind in this respect as well. Figure 5 looks at the efficiency in the creation of knowledge, using patents as a proxy, and finds that Latin America has substantially lower elasticities of patents with respect to R\&D than comparator countries. Since the microeconomic studies generally find elasticities around 0.5 in the region,

\footnotetext{
${ }^{6}$ See Maloney (2002) for an application of this view to the underperformance in terms of natural resources displayed by Latin America.
} 
FIGURE 5

Selected countries: Elasticity of knowledge creation, 1960-2000 (Percentages)

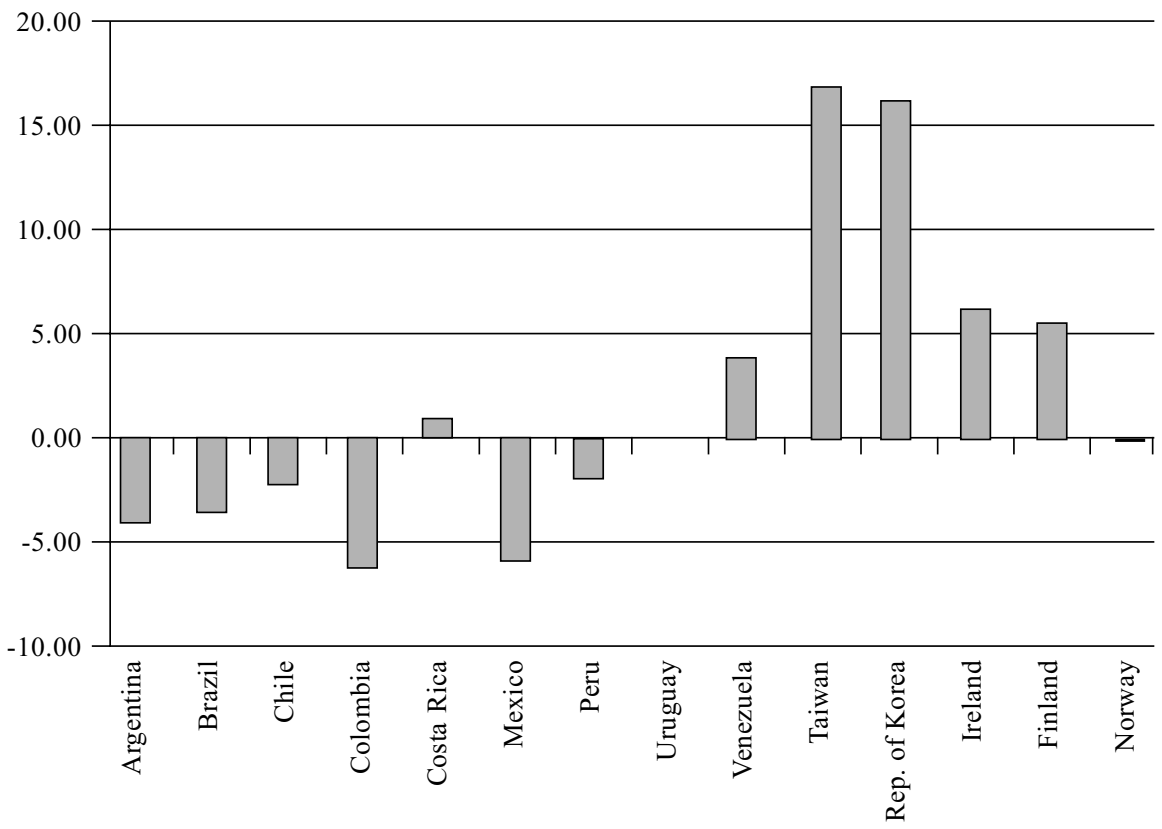

Source: Bosch, Lederman and Maloney (2004).

FIGURE 6

Selected countries: Subjective evaluation of research quality and degree of collaboration, 2002

(Seven point response scale)

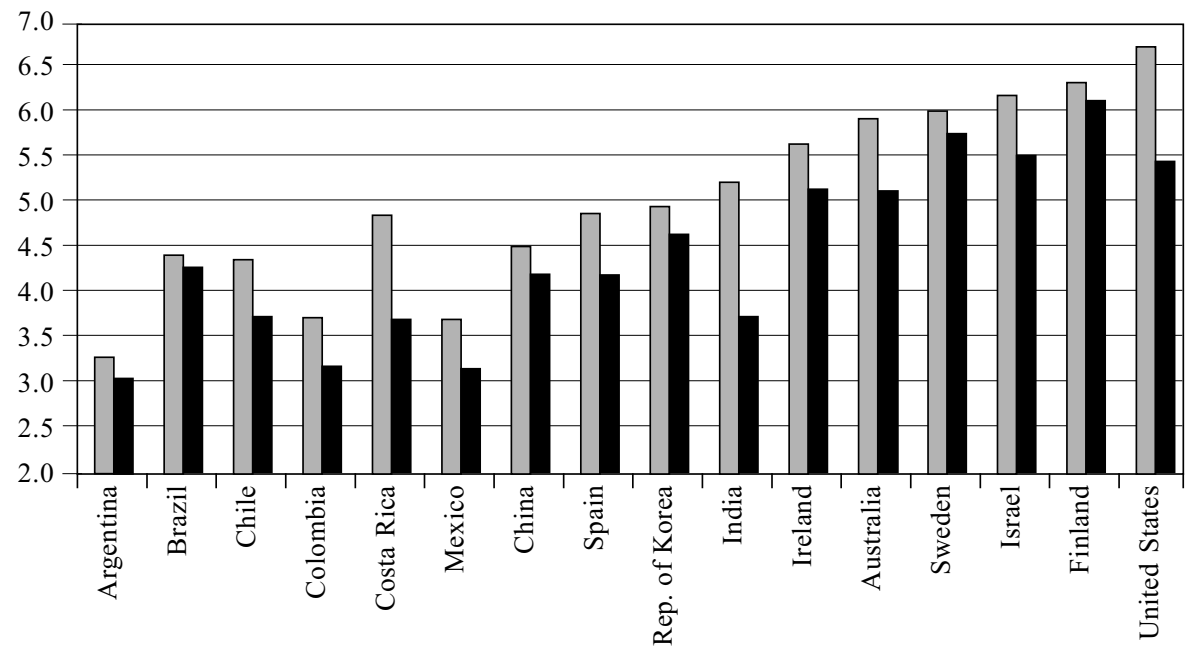

Quality of scientific institutions

Cooperation between universities and private sector

Source: World Economic Forum (2002). 
whereas the OECD is closer to 1 , the lower performance of the Latin American countries suggests that they are less able to exploit knowledge spillovers than they ought to be. Figure 6, which reports the subjective responses of entrepreneurs to a World Economic Forum questionnaire, suggests that Latin America does quite poorly on a 7 point scale as regards the degree of interaction between the private sector and research centers. In turn, this may reflect the generally low opinion that the private sector has of the local research centres. ${ }^{7}$
It also appears that in the region overall, roughly $60 \%$ of $R \& D$ resources are devoted to basic research, whereas the comparable figure for the United States is $15 \%$, and a very low percentage is carried on or financed by the private sector, contrary to what happens in countries that are more effective in this respect. This suggests some misalignment between the incentives given to the institutions doing research and the actual needs of the local economies, as well as a lack of incentives for private firms to engage in R\&D activities themselves.

\section{Specific policies and institutions for fostering innovation}

Since, there is as yet no set of best practices in the OECD that can be easily extrapolated to the Latin American context, in this section we seek only to set forth some considerations emerging from the literature that could be useful for policy making. ${ }^{8}$

\section{Dealing with appropriability and spillovers of innovation: intellectual property rights versus subsidies and tax credits}

The potential high spillovers of innovation imply that social returns are much higher than private returns and thus the innovative effort of individual firms, left to themselves, would be suboptimal from a social point of view, even if barriers and artificial disincentives were removed. Two types of instruments have been used to deal with this problem: intellectual property rights, and public subsidies (through different means such as public supply, matching grants, or tax credits).

Traditionally, the transition process from scientific activity to technological breakthroughs and their development, application and diffusion has been seen as a linear process in which spillovers are higher at the scientific end and lower at the applied end. This view leads to the concentration of public subsidies at the

\footnotetext{
${ }^{7}$ Both the variables considered in figure 6 appear to be correlated with the elasticity of knowledge creation, as also are education levels and intellectual property rights (Bosch, Lederman and Maloney, 2005).

${ }^{8}$ This section draws heavily on Maloney (2005a).
}

scientific and basic technological research level (which in many countries is fully financed by public resources assigned to universities and public research institutes) and the use of "strong" intellectual property rights at the more applied side of the process, since such rights help to solve the appropriability problem at the expense of actually reducing spillovers and diffusion (since imitators or users must now pay a royalty cost).

Romer (2005) and Rosenberg $(2005)^{9}$ have argued that this view is incorrect, as in practice there is a strong backwards feedback loop from application to technological and scientific discovery: many, if not most scientific breakthroughs have emerged from attempts to solve concrete problems at the production end and the basic questions and problems that such attempts have posed to more basic technological and scientific research. Hence, it makes sense to distribute public subsidies more evenly across the process, using matching grants or tax credits at the applied side, and relying less on "strong" intellectual property rights for stimulating applied technological R\&D. This parallels the discussion about the relative efficiency of supply and demand side subsidies in other areas: subsidies should be oriented not only to the supply side (basic scientific and technological capacity and activities), but

\footnotetext{
${ }^{9}$ Both these papers were presented at the Conference on "R\&D and Innovation in the Development Process: A New Look at Theory, Evidence and Policies", (World Bank/Universitat Pompeu Fabra, Barcelona, 9-11 June 2005).
} 
should also aim to stimulate demand for innovation from firms. ${ }^{10}$

Authors like these thus question whether the orientation given to trade-related intellectual property rights in the World Trade Organization (WTO) may not be inefficient from a systemic point of view. Deciding the precise kind of intellectual property rights which are most appropriate for countries at a level of development similar to that of Latin America is beyond the scope of this paper, and the reader is referred to the broad literature on this subject. ${ }^{11}$

What we should consider here is the relative efficiency of tax credits versus direct subsidies (e.g., under matching fund schemes) to stimulate firms' demand for innovation. Arguments in favour of tax credits for R\&D expenditure rather than direct subsidies point to potential rent seeking and other government failures in "selecting winners" through subsidy schemes. However, the inefficiencies of tax credits are also well known: i) they are not proportional to the difference between social and private rates of return, as they should be, but instead to R\&D costs; ii) in most cases, they are proportional to total annual R\&D costs, and although this may lead to some marginal R\&D projects being executed, most of the resources will benefit intra-marginal R\&D that would be carried out anyway. In such cases, benefits will be low compared to the high fiscal costs. Some countries, like the United States, have attempted to design an incremental "R\&D" tax credit, but problems related to the definition and measurement of the corresponding "base" are huge; iii) they create an incentive to artificially classify nonR\&D expenses as R\&D, which may not be easy for tax authorities to detect, especially in developing countries where technical and administrative capacities are low.

Some studies -although they do not include a cost/ benefit analysis- have found that tax credits do indeed increase private $R \& D$ in OECD countries. In most of the Latin American countries, however, where tax regimes are already full of exemptions, tax credits and loopholes, and where administrative capacity is weak, it is highly doubtful that the fiscal costs would not be large in comparison to the potential benefits. Probably only countries like Chile and Brazil, which have shown that they can enforce tax laws with some effectiveness,

\footnotetext{
${ }^{10}$ In order to satisfy their demand for technology transfer, creation or adaptation, firms may build their own R\&D supply capacity at home, contract the work out to universities, research centres, etc., or, more usually, use a combination of both methods.

${ }^{11}$ See, for instance, Maskus (2000) and Fink and Maskus (2005).
}

should think of trying out this instrument. We would not recommend it for most of the Latin American and Caribbean countries at this stage, however.

Instead, efforts might initially be devoted to improving the design of the subsidy schemes that already exist in many countries in the region, thereby possibly overcoming these problems (as well as serving as a good instrument to promote cooperation between firms and universities/research Institutes and to foment R\&D by the latter on public goods - health, the environment, etc.). Some of these schemes have proven quite effective, but in other cases there seems to be too much duplication and lack of efficiency criteria. ${ }^{12}$ Examining successful experiences around the world, some general guidelines can be extracted on how to maximize their potential benefits, while mitigating the risks of rent seeking and government failure:

i) First, there is the issue of governance: who regulates and administers the system? To reduce the probability of government failures and rent seeking and ensure commercial relevance, it is advisable to ensure participation by the private sector -through broad business associations - and the academic world. In view of the limited size of the science and technology community in most Latin American and Caribbean countries and the fact that local knowledge will not be at the frontier in many areas, approval of schemes in specific areas should be given by expert committees which should include foreign experts. Although Finland is now at the frontier of technological creation in many areas, its highly successful national technology agency (TEKES) nevertheless makes routine pilgrimages to the Massachusetts Institute of Technology (мІт), the National Science Foundation (NSF) and other global centers of advanced knowledge in order to identify emerging new directions of technological research.

ii) Second, there is the issue of the size of the subsidy. Theoretically, it would be desirable to make it proportional to the difference between social and private rates of return, but this is quite difficult in practice. Perhaps it would be useful to specify ex ante a range for the matching contribution to costs (estimates suggest that this should be around the level of $50 \%$ or more to be effective, in line with the OECD's usual benchmark), while leaving some discretion to the experts and the competent authorities for classifying proposals in a few categories (with different rates of subsidy), depending

\footnotetext{
${ }^{12}$ See Sanguinetti (2004) for Argentina, and Benavente (2004) for Chile.
} 
on their assessment of how large the spillovers may be with respect to costs. Some categories of research (on public goods, or basic technological research with a wide array of potential applications) could systematically receive higher proportions of subsidy than others. Alternatively, it has been suggested that the ratio of subsidy should not be fixed administratively (Link and Scott, 2004), but should be subject to competitive bidding so as to guarantee that hurdle rates are met, but not widely exceeded. However, this can at best be only one of several selection criteria, as otherwise there would be a bias towards selection of projects with low differences between the social and private rates of return.

iii) Third, there is the issue of the allocation of funds among various areas or the promotion of "strategic" areas. Some highly successful countries like Finland have found it appropriate to concentrate support in a few broad areas in which there is already some capacity and activity and in which the country is deemed to be competitive (so as to avoid a narrow approach involving "picking winners", but at the same time seeking to avoid spreading scarce resources and evaluation capacities too thinly). Thus, it might make sense to either give priority (other things being equal) or to pre-allocate part of the funds to a few well-selected broad areas in which there is already revealed comparative advantage (as measured, for example, by export ratios and export dynamism) or strong reasons to believe that comparative advantage can be easily developed. Even so, some funds should be reserved for "open" competition, as development of new, unexpected activities or exports might be quite critical for growth (Hausmann and Rodrik, 2003). Furthermore, some critical areas of non-tradables which have important public good characteristics, such as tropical health, or which involve environmental and infrastructural issues, might also be pre-specified as priority "strategic" areas. In any case, care must be taken to prevent such "sectoral" allocations from becoming areas of rent-seeking by business or academic groups.

iv) Fourth, given the importance of developing stronger ties between universities and research centres or institutes and firms in Latin America, priority could be given to proposals that involve cooperation. Also, given the low contribution currently made by firms in much of the region, some priority could be given to proposals presented and partially financed by productive firms. Participation by small and mediumsized enterprises could also receive some priority. Such characteristics might "add" points for the final selection, but the overriding criteria should be "technical soundness and capacity" and "relevance and potential spillovers." In Chile, the Production Development Corporation (CORFO), the National Commission for Scientific and Technological Research (CONYCIT) and the National Foundation for Agricultural Innovation (FIA) recently launched a special programme to stimulate such forms of cooperation.

v) Finally, in view of the importance of experimentation and learning in this area, careful monitoring and evaluation systems should be established from the start.

\section{The role of universities and public research institutes}

Given that the capacity to undertake major R\&D activities requires a critical mass and that spillovers might be higher at the scientific and basic technological research level (as well as in the area of public goods), there is clearly a role for specialized science and technology institutions. It is no surprise, then, that such non-market R\&D institutions have developed everywhere. Research centres are often part of or related to universities, given the big synergies and interrelations between innovation and specialized skills in the modern world. Indeed, most R\&D in Latin America (perhaps too much, as discussed above) has so far been carried out by such entities, especially universities, but unfortunately often in splendid isolation from the productive sector and with too much concentration on the "basic" research side. Most agricultural and natural resource-related research, in particular, has been carried out by public research institutes, with mixed results (De Ferranti, Perry, Lederman and Valdés, 2004). The key issue to be tackled is thus how to enhance cooperation between such institutions and the productive sector and how to stimulate more relevant and applied technological research. Some guidelines derived from successful experiences are the following:

i) Funding for research in such agencies should increasingly be obtained through competition rather than entitlement. This has already begun to happen in some countries in the region.

ii) However, given the need to maintain critical mass and some degree of continuity in the science and technology field, there is a need to balance "basic financing" (whose amount should be reviewed every few years against performance) and competitive finance for programmes and projects through the matching grant funds discussed above. It is possible to go too far 
in the direction of competitive programme/project financing, as the New Zealand experience shows and as seems to have happened with agricultural research reform in some Latin American countries in recent years. Finland's VTT technological research centre combines about $25 \%$ base financing for research institutes, with nearly $25 \%$ private finance and around $50 \%$ matching grants from the TEKES national technological agency.

iii) The structure of incentives to researchers is critical: both promotion and rewards should depend on performance. The way intellectual property rights are allocated is also critical: though universities or institutes might keep a part of the royalties from possible patents (as a reward for the risks they run in supporting and partially funding research), most of them should go the researchers themselves. The allocation of intellectual property rights among firms, universities and researchers in the case of R\&D contracted by firms or carried out under cooperative arrangements is also crucial. Little progress has been made so far in Latin America in these areas, in contrast to what happened long ago in the United States with the Bayh-Dole Act of $1980,{ }^{13}$ whose evaluations are generally positive (though not fully conclusive).

iv) Infrastructure is also important: laboratories, technology transfer offices, etc. The purpose of the latter offices is to develop networks of industrial partners, set up guidelines for the commercialization of research results and manage the intellectual property rights of universities, science parks and incubators. Many Latin American universities have began to create such offices to carry out some of these functions, though few of them are really effective yet.

v) All kinds of links between firms and universities and research institutes should be encouraged (not just links in respect of R\&D): student practices, specialized training, and advisory and consultancy services. Some Latin American universities have also begun to move strongly in such directions, especially in countries where there is more competition among public and private universities.

vi) Finally, governance and culture are key elements. The presence of private sector representatives on university and research institutes boards and committees could be quite useful in this regard. However, there might be a more basic cultural problem in many Latin American universities which evolved

\footnotetext{
${ }^{13}$ Patent and Trademark Law Amendment Act (1980).
}

from the more monastic humanistic conception prevalent in Continental Europe and which show some reluctance to mix in "worldly affairs" and to play a more practical role, especially as the handmaidens of industry. Overcoming this requires a profound national debate on the role and purpose of universities.

\section{Other specialized institutions}

There are other important functions within the national innovation system that demand the existence of specialized public, private or hybrid institutions that will act as "honest brokers" with no direct market interest in the outcomes (Link and Scott, 2004). The most important are:

i) Promulgation and adoption of standards and certification.

ii) Extension services to transfer technologies and management techniques, especially in sectors such as light industry and agriculture, where the predominantly small size of the enterprises implies lower appropriability of the benefits of the adoption of technologies and credit and information constraints are larger.

iii) Coordination and facilitation of cooperative R\&D efforts joining industry, government and universities in research projects subsidized by the government, as well as oversight functions in respect of publicly funded or subsidized private research.

iv) Serving as international "antennae", to identify new directions in technology and R\&D and foster cooperation with international institutions in specific areas.

Institutions that carry on functions i) and ii) above are common (though not always effective) in Latin America and the Caribbean. Fundación Chile is a very successful example of an institution that carries on activities in areas ii), iii) and iv) above, but it has proved difficult to replicate it successfully in other countries of the region.

\section{Innovation clusters}

Since innovation (and skill enhancing) spillovers are often mainly limited to a particular sector or to a group of inter-related firms (including suppliers, distributors and users), it makes sense to tailor and concentrate part of the innovation policy support on "innovation clusters" that may internalize many of the externalities of the innovation process. The key here seems to be to support emerging clusters (where the private sector 
itself has taken the initiative) and not to attempt to promote them from scratch.

The national innovation system may efficiently contain some sectoral innovation systems. However, cluster-type policies can be a complement to but not a substitute for a properly functioning overall national innovation system, as the latter must facilitate the emergence of industries that are not on the government's radar screen. Israel and Finland seem to have been able to reach a good balance between a strong and efficient overall national innovation system, complemented with a few sectoral clusters.

Clusters should essentially be vehicles for efficient public/private cooperation to solve market and coordination failures, not just to promote innovation and skill enhancement. They can be extremely useful for identifying constraints and coordination failures in supplies, infrastructure (particularly in transport), marketing, attraction of foreign direct investment, etc. However, they can also lead either to rent-seeking behaviour (through unwarranted protection and inefficient or inequitable subsidies) or to artificial and costly development of local suppliers. In particular, the encouragement of "vertical" clusters -which were historically considered to be of key importance in many countries- may lead to very inefficient outcomes in today's world of much lower communications and transport times and costs and higher international production integration within production chains (De Ferranti, Perry, Lederman and Maloney, 2002).

\section{International connections}

Given that most of the development of new technologies (and other innovations) will continue to take place internationally (and, in fact, in only a few countries, multinational firms and centres of excellence), it is highly important that the national innovation system should be highly international in character. International links among firms, ${ }^{14}$ among universities and among local firms and foreign universities are essential and should be stimulated by innovation policies.

International circulation of the best brains, in particular, is central to the operation of an efficient national innovation system, as a considerable proportion of knowledge transfers and cooperation in innovation still depends on individuals and the contacts between them. Individuals learning in centres of excellence or working in firms and institutions that are leaders in innovation (or even simply more advanced than domestic agents) can become catalytic agents for innovation and change upon their return to their own countries. Likewise, hiring foreign researchers, technicians, managers and business advisors or temporarily bringing them in through institutional exchanges or other means may help enormously to spur innovation and change. Governments, universities, research institutes and firms should therefore stimulate such interchanges. International temporary immigration agreements (such as that currently being discussed between the United States and Mexico) and advances in the World Trade Organization on the movement of persons could be an important part of the international dimension of innovation policies.

Even the feared (and initially costly) "brain drain" can eventually be turned into an advantage. The Russian-Jewish, Chinese, Irish and Indian diasporas have come to play a crucial role in this regard (as well as in opening trade and FDI opportunities) for Israel, China, Ireland and India, respectively, often triggered when sensible policies in these countries created a strong investment, innovation and growth environment. Some Latin American countries (governments, private sector and research community working jointly or sometimes independently) are beginning to organize effective networks of their skilled nationals who have emigrated to the United States, Europe and other regions and to stimulate their involvement with different public and private initiatives at home. Such policies may give significant pay-offs in the future.

\footnotetext{
14 A significant number of technology transfers and innovations happen through interaction with and support from foreign suppliers and buyers.
} 


\section{VI}

\section{A link back to equity?}

Moving away from science and technology to a more general innovation agenda allows us to establish a link back to the second focus of this conference, equity, and more generally to the important complementarities of human and other innovation-related capital stressed in De Ferranti, Perry, Guasch and others (2003).

Recent thinking suggests that Latin America's persistent wealth inequality may have played a role in slowing the region's ability to adopt foreign technologies. ${ }^{15}$ Engerman, Haber and Sokoloff (2000) argue that the period of sustained economic growth during the eighteenth and early nineteenth centuries that distinguished the United States and Canada from the other New World economies was fundamentally due to the patterns of settlement and crops, which led to a relatively unequal distribution of income in the slowergrowing areas. This concentration preserved the political influence of the advantaged elites and led to the marginalization of much of the population, as measured by lower access to enfranchisement, natural resources, financial institutions and property rights, as well as primary schooling.

The lower access to education may have been particularly important. The concerns with social control, extreme inequality of income, weak public finance, and perhaps an intellectual commitment to a small State sector, all led to dramatically smaller efforts in Latin America, as compared with the successful natural resource exporters, towards the achievement of universal education. By 1870 , more than $70 \%$ of the population aged 10 or above in Australia, the United States, Canada, and Sweden was literate: three times the percentage in Argentina, Chile, Costa Rica and Cuba, and four times the percentage in Brazil and Mexico. Latin America progressed unevenly towards higher levels over the next half century. By 1925, Argentina, Uruguay, Chile and Costa Rica had attained literacy rates of over $66 \%$, while Mexico, Brazil, Venezuela, Peru, Colombia, Bolivia, Guatemala and Honduras continued to hover around 30\% until much later (Mariscal and Sokoloff, 2000).

As Engerman and Sokoloff (1997, p. 287) note, this is particularly important because early

${ }^{15}$ See Maloney (2002) for more discussion. industrialization reflected the cumulative impact of incremental advances made by individuals throughout the economy, rather than being driven by progress in a single industry or the actions of a narrow elite. They note -as one manifestation critical to the development of innovation- that the greater equality in human capital accounted partially for the high rates of invention in the United States overall. They also argue that "the more general concern with the opportunities for extracting returns from inventions contributed to a patent system which was probably, at the time, the most favorable in the world to common people. This stands in stark contrast to Mexico and Brazil, where patents were restricted by costs and procedures to the wealthy or influential, and where the rights to organize corporations and financial institutions were granted sparingly, largely to protect the value of rights already held by powerful interests."

Blomström and Kokko (2001) argue that in Sweden, the introduction of a mandatory school system in 1842 and emphasis on literacy and numeracy was a key factor in the ability of individuals and firms to learn and adopt new technologies: much elementary learning and technology transfer was based on written instructions such as blueprints and handbooks. This also suggests that the extensive literature comparing Argentina and Australia may be missing a critical point. Despite a strong feeling of "there but for the grace of God go we" on the part of Australian authors, it is very clear that, in the mid-nineteenth century, Australia was far closer to the industrialized countries in levels of literacy; and this, in a country that until the 1840s was a penal colony of the United Kingdom! The story of the global conglomerate Broken Hill Proprietary Company, Ltd. (BHP), started by a boundary rider on a sheep station, shows the importance of a broad base of literate citizens who can grasp new ideas and have the benefit of institutions that provide support in this field.

A recent study by Klinger and Lederman (2005) suggests that such impacts are still relevant and seeks to explain two dimensions of innovation. The first is discovery, measured as new export industries introduced (as argued by Hausmann and Rodrik, 2003), and the second is patenting activity. The first understates innovative activity for advanced countries, since their 
industrial structures are already quite complete and new exports will need to be "invented", while patenting activity understates overall innovative activity in poor countries, where diffusion of existing technologies may be more the order of the day. Using both measures, Klinger and Lederman find that population is, as might be expected, a significant determinant. In addition, however, poverty, the Gini coefficient for income distribution and the proportion of the labour force with secondary education also enter significantly. This can be interpreted as meaning that the "effective innovative population" is important for the generation of new ideas and growth. In so far as Latin America has reduced its effective innovative population by keeping education, wealth and access to institutions restricted to a relatively narrow elite, growth in total factor productivity is likely to have been hampered.

Furthermore, in societies where the elites heavily emphasized theology and philosophy (economics may be considered as the $20^{\text {th }}$ century equivalent in this respect) and showed a disdain for applied fields such as engineering, the very skewed access to education and low social mobility is likely to have restricted the supply of aspiring middle-class workers who formed the backbone of the inventive and/or engineering classes in the advanced countries. Once again, as table 1 shows, the difference of Colombia and Chile, on the one hand, and Australia on the other at the turn of the $20^{\text {th }}$ century in terms of the density of engineers in the population is dramatic. The lost opportunities in terms of cumulative learning by doing locked the region into a dependent relationship with the advanced countries not only in the invention of new technological know-how, but also its diffusion.

TABLE 1

Selected countries: Density of engineers at the turn of the twentieth century

\begin{tabular}{lcc}
\hline Country & Year & $\begin{array}{c}\text { Engineers per } \\
100,000 \text { workers }\end{array}$ \\
\hline Australia & 1920 & 47 \\
Chile & 1930 & 6 \\
Colombia & 1887 & 8 \\
Sweden & 1890 & 84 \\
United States & 1920 & 128 \\
\hline
\end{tabular}

Source: Maloney (2002).

\section{VII}

\section{Conclusions: the need for} a comprehensive view

Latin America and the Caribbean have an innovation problem in addition to the gap in accumulation, and this problem manifests itself both in the level of innovative effort in many areas and also in the way this effort spills over to other actors in the economy. Thus, innovation appears to merit an important place on the policy agenda.

Innovation policy goes beyond science and technology policy. Even if we accept deficient total factor productivity as being entirely due to low levels of technological progress and not inefficiencies, this still leaves numerous areas that need to be addressed, such as barriers to the creation of more innovative firms, deficient absorptive capacity of firms, internal obstacles (labour legislation, for instance) or credit market barriers to the adoption of extant technologies, and weak science and technology infrastructure and lack of incentives to innovate. Hence promoting innovation requires a broader vision of the factors that could impede it and therefore a broader set of diagnostics than those related to science and technology per se. Stimulating innovation in these broader areas requires that attention be focused on the capabilities of firms and incentives for enhancing them: developing entrepreneurial skill and a taste for innovation, and dealing with both innovation- and non-innovation related barriers and market failures that hamper broadbased productivity growth.

The capabilities of firms in terms of technological upgrading are of fundamental importance. Although the discussion often takes place at the aggregate level, productivity growth is primarily a firm-level phenomenon. If there is no demand for innovation on the part of the private sector, efforts to improve science and technology capacity on the supply side will be ineffectual. Fundamentally, spending public money to 
provide a public good in this field will be "pushing on a string" and will not lead to productivity growth unless the private sector takes up the challenge.

The private sector of the Latin American and Caribbean countries must prepare itself for this transition. Although the composition of their various innovative activities is similar to that of their European counterparts, the magnitude of the private sector's efforts in the region is extremely low, especially in training and knowledge acquisition, but also in R\&D. This is especially regrettable in the case of the larger firms, since they would seem to be less subject to information, credit or other restrictions, and should be closer to the frontier in their respective sectors. The private sector needs to increase its awareness of this and its innovation effort in order to be able to absorb knowledge generated elsewhere in the national innovation system and abroad.

This will require going beyond measures to increase the stock of well-trained human capital and research units: steps must also be taken to improve the diffusion of knowledge across units. Evidence from the OECD suggests that, at the micro level, knowledge generation exhibits decreasing returns to scale, while at the aggregate level, it shows constant returns to scale. This suggests that there are substantial knowledge spillovers among individuals and firms in the economy.
When knowledge creation shows diminishing returns at the national level, this suggests that such spillovers may be less prevalent (Bosch, Lederman and Maloney, 2005). Generally, the degree of spillovers appears to be correlated with such factors as the level of education, perceived quality of research institutes, degree of collaboration between research institutes and the private sector, and intellectual property. These are central aspects of policy design in the context of a national innovation system.

The Latin American and Caribbean countries, then, must begin by making the necessary reforms to secure a better functioning national innovation system and to lay the foundations for full participation in the international science and technology community. Even if, at present, less exotic sources of productivity growth could be exploited, it should be borne in mind that, in practice, reform of the national innovation system and particularly that related to the science and technology system may easily take several decades. It will be necessary to realign incentives, build the required institutions, and reform or dismantle those that are currently inefficient, while identifying successful interventions, and all this probably needs to be begun now.

Pro-equity policies may, in the long run, stimulate growth by enlisting a greater number of individuals in the innovation effort.

\section{Bibliography}

Benavente, J. (2002): The impact of public financing and research groups on innovative activities in Chilean industry, Washington, D.C., World Bank, unpublished.

(2004): Investigación y desarrollo, innovación y productividad: un análisis econométrico a nivel de la firma, Santiago, Chile, University of Chile, unpublished.

Bergoeing, R., A. Hernando and A. Repetto (2003): The effect of policy distortions on productivity dynamics, Santiago, Chile, Centre for Applied Economics, University of Chile, unpublished.

Blomström, M. and A. Kokko (2001): From Natural Resources to High-tech Production: The Evolution of Industrial Competitiveness in Sweden and Finland, Stockholm, Stockholm School of Economics.

Blomström, M., A. Kokko and F. Sjoholm (2002): Growth and innovation policies for a knowledge economy: experiences from Finland, Sweden, and Singapore, Washington, D.C., World Bank, unpublished.

Bosch, M., D. Lederman and W. Maloney (2005): Patenting and Research and Development: a Global View, Policy Research Working Paper, No. 3739, Washington, D.C., World Bank.

Caballero, R., K. Cowan and others (2004): Effective Labor Regulation and Microeconomic Flexibility, Cowles Foundation Discussion Paper, No. 1480, New Haven, Connecticut, Cowles Foundation for Economic Research.
Caselli, F. and S. Tenreyro (2004): Is Poland the Next Spain?, Discussion Paper 04-8, Boston, Federal Reserve Bank of Boston. Chen, D. and C. Dahlman (2004): Knowledge and Development: A Cross-Section Approach, Policy Research Working Paper Series, No. 3366, Washington, D.C., World Bank.

Chen, D. and C. Dahlman (2004): Knowledge and Development: A Cross-Section Approach, Policy Research Working Paper Series, No. 3366, Washington, D.C., World Bank.

Cohen, W.M. and D.A. Levinthal (1989): Innovation and learning: the two faces of R\&D, Economic Journal, vol. 99, No. 397, London, Royal Economic Society.

Comin, D. (2004): R\&D: A Small Contribution to Productivity Growth, NBER Working Paper, No. 10625, Cambridge, Massachusetts, National Bureau of Economic Research.

De Ferranti, D., G. Perry, D. Lederman and W. Maloney (2002): From Natural Resources to the Knowledge Economy. Trade and Job Quality, Washington, D.C., World Bank.

De Ferranti, D., G. Perry, L. Guasch and others (2003): Closing the Gap in Education and Technology, Washington, D.C., World Bank.

De Ferranti, D., G. Perry, D. Lederman and A. Valdés (2004): Beyond the City. The Rural Contribution to Development, Washington, D.C., World Bank.

Engerman, S. and K. Sokoloff (1997): Factor endowments, institutions, and differential paths of growth among new world 
economies: a view from economic historians of the United States, in S. Haber (ed.), How Latin America Fall Behind. Essays on the Economic Histories of Brazil and Mexico, 18001914, Stanford, California, Stanford University Press.

Engerman, S., S. Haber and K. Sokoloff (2000): Inequality, institutions, and differential paths of growth among new world economies: a view from economic historians of the United States, in C. Menard (ed.), Institutions, Contracts and Organizations, Northhampton, Massachusetts, Edward Elgar.

Fink, C. and K.E. Maskus (2005): Intellectual Property and Development: Lessons from Recent Economic Research, Washington, D.C., Oxford University Press/World Bank.

Hausmann, R. and D. Rodrik (2003): Economic development as self-discovery, Journal of Development Economics, vol. 72, No. 2, Amsterdam, Elsevier, December.

Howitt, P. and D. Mayer-Foulkes (2005): R\&D, implementation and stagnation: a Schumpeterian theory of convergence clubs, Journal of Money, Credit and Banking, vol. 37, No. 1, Columbus, Ohio, Ohio State University Press, February.

Klinger, B. and D. Lederman (2005): Sectoral concentration in the search for innovations and export booms, Washington, D.C., World Bank, unpublished.

Lederman, D. and W. Maloney (2003): R\&D and development, Washington, D.C., World Bank, unpublished.

Link, A. and J. Scott (2004): The role of public research institutions in a national innovation system: an economic perspective, Washington, D.C., World Bank, unpublished.

Maloney, W. (2002): Missed opportunities: innovation and resourcebased growth in Latin America, Economia, vol. 3, No. 1, Washington, D.C., Brookings Institution Press.

(2005a): Innovation policies in Latin America: a guide to the background papers commissioned for innovation policies II, Washington, D.C., World Bank, unpublished.

(2005b): Patterns of innovation, Washington, D.C., World Bank, unpublished.
Maloney, W. and A. Rodriguez-Clare (2005): Innovation shortfalls, Washington, D.C., World Bank, unpublished.

Marimón, R. (2005): Innovation in Spain: past and future challenges, Washington, D.C., World Bank, unpublished.

Mariscal, E. and K. Sokoloff (2000): Schooling, suffrage, and the persistence of inequality in the Americas, 1800-1945, in S. Haber (ed.), Political Institutions and Economic Growth in Latin America. Essays in Policy, History and Political Economy, Stanford, Stanford University.

Maskus, K.E. (2000): Intellectual Property Rights in the Global Economy, Washington, D.C., Institute for International Economics, Washington D.C.

Meller, P. (2001): Chilean Copper: Facts, Role and Issues, Washington, D.C., World Bank.

OECD (Organisation for Economic Co-operation and Development) (2004): Science, Technology and Industry Outlook, 2004, Paris.

Pinto, A. (1959): Chile, un caso de desarrollo frustrado, Santiago, Chile, Editorial Universitaria.

Romer, P. (2005): The Arc of Science, document presented at the Conference on "R\&D and Innovation in the Development Process: A New Look at Theory, Evidence and Policies" (Barcelona, June 2005), unpublished.

Rosenberg, N. (2005): Science and Technology: Which way does the causation run?, document presented at the Conference on "R\&D and Innovation in the Development Process: A New Look at Theory, Evidence and Policies" (Barcelona, June 2005), unpublished

Sanguinetti, P. (2004): Innovation and $R \& D$ expenditures in Argentina: evidence from a firm level survey, Buenos Aires, Universidad Torcuato di Tella, unpublished.

World Economic Forum (2002): The Global Competitiveness Report, 2001-2002, Geneva.

Wright, G. (2001): Resource Based Growth, Then and Now, Washington, D.C., Stanford University/World Bank. 